\title{
Light-controlled inhibition of MLL1 methyltransferase by azo-containing peptides: Towards optoepigenetic leukemia regulation
}

\author{
Lea Albert ${ }^{1}$, Jing $\mathrm{Xu}^{2}$, Vasundara Srinivasan ${ }^{1}$, Yali $\mathrm{Dou}^{2}$, Olalla Vázquez ${ }^{1}$ \\ ${ }^{1}$ Philipps-Universitat Marburg, Germany \\ ${ }^{2}$ University of Michigan, United States
}

https://doi.org/10.17952/35EPS.2018.067

Epigenetics studies the variation in gene expression unrelated to changes in the DNA sequence. Epigenetic regulation includes chemical modulation at both, nucleic acid and protein level. Thus, one of the main mechanisms of control are the post-translational modifications (PTMs) on the histone proteins, which have context-dependent effects, together with the complex cross-talks between the responsible protein machinerieshistone language.[1] Following the language metaphor, such epigenetic proteins can be divided into three classes: writers, erasers and readers that add, remove or reorganize these PTMs, respectively. Consequently, gene expression is ruled by a dy-namic signaling network of protein-protein interactions (PPIs). Particularly, we are interested in the PPI between the mixed-lineage leukemia 1 (MLL1) histone methyltransferase and the WD40repeat protein 5 (WDR5) since it is key for MLL1 activity (Figure 1). In particular, this interaction is established between the arginine binding pocket of WDR5 and the WDR5-INteracting (WIN) motif of MLL1 (Ac-GSARAEVHLRKS-NH ${ }_{2}$ ).[2]

MLL1 is mostly found in the promoter regions of actively transcribed genes and is essential for hematopoiesis during embryogenesis.[3] Importantly disregulation of MLL1 as well as overexpression of MLL1 target genes are related to acute myeloid leukemia (AML), acute lymphoblastic leukemia (ALL) and some solid tumors.[4,5] Thus, MLL1 is a promising therapeutic target in cancer research.

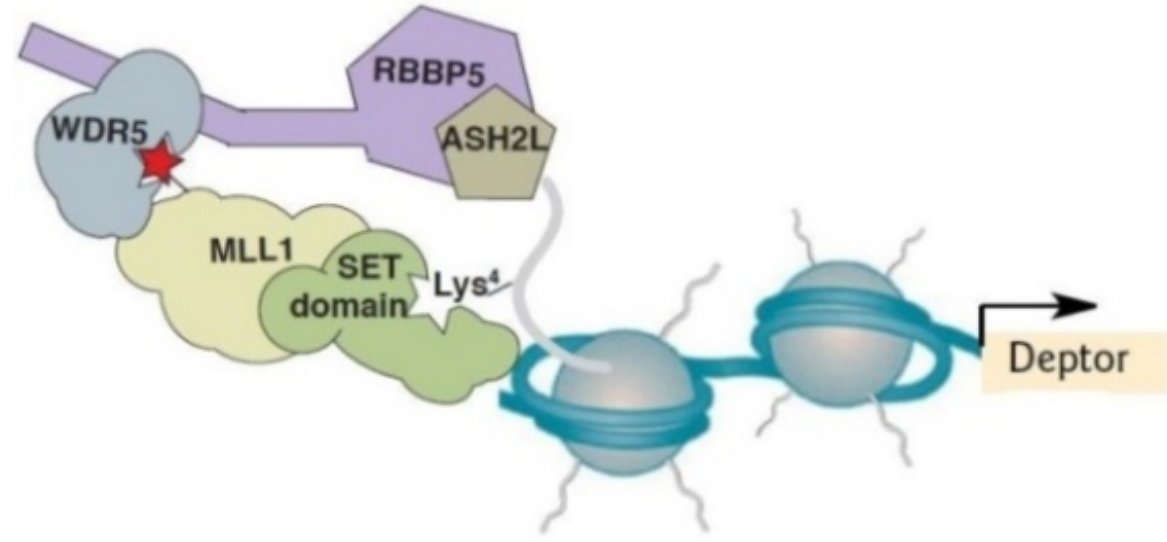

Figure 1: MLL1 core complex, whose formation is needed for H3K4 methylation activity of MLL1 enzyme.

Photopharmacology, which aims at using light as an external non-invasive trigger to modulate drug activity, has recently grown into a brilliant field. In the context of epigenetics and before our work,[6] there have only been two precedents of reversible regulation of a histone-modifying enzyme: the histone deacetylase (HDAC).[7,8] To our knowledge, there were not any photocontrollable probes for methyltransferases at that time and in both former examples photoswitchable small-molecule inhibitors bind to the HDAC catalytic domain directly.

In contrast to theses precedents, we envisioned the reversible control of MLL1 indirectly through targeting the essential MLL1-WDR5 PPI. Since we were targeting PPIs, designing photoswitchable peptidomimemtics as inhibitors was advantageous over small-molecules (Figure 2). Our strategy is based on the truncation of the WIN peptide: $\mathrm{NH}_{2} \mathrm{SARAEVHLRKSNH} \mathrm{H}_{2}(1)$, which interacts with higher affinity than the parent WIN peptide $(\mathrm{Ki}=$ $160 \mathrm{nM}$ for WIN, $\mathrm{Ki}=20 \mathrm{nM}$ for 1).[9] The -ARA- sequence was identified as the crucial motif for WDR5 recognition.[9] 


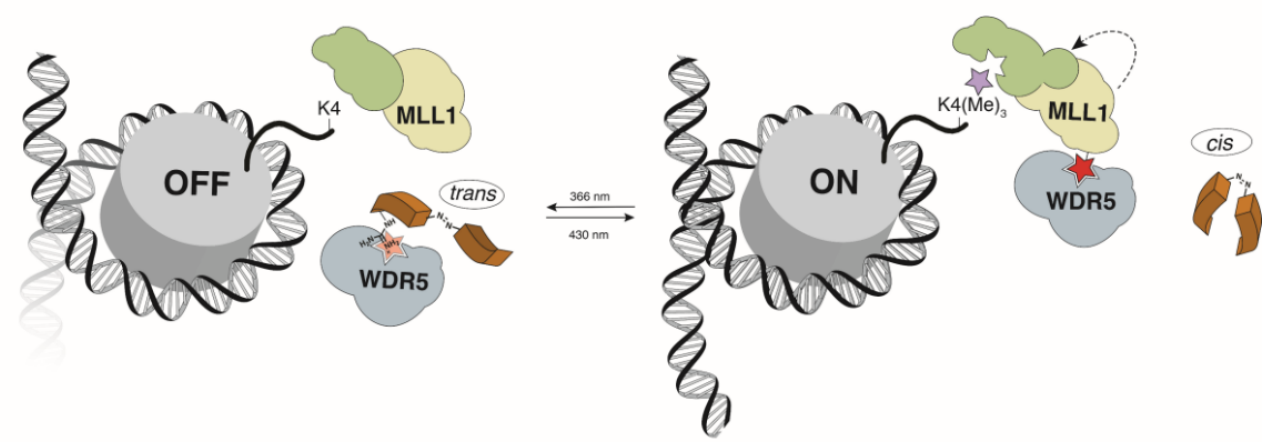

Figure 2: Strategy for MLL1 control through photoswitchable peptidomimetics via indirect targeting of MLL1-WDR5 PPI.

As an initial proof of concept, we chose the classic (4-aminomethyl)phenylazobenzoic acid (AMPB) (Figure 3) as a molecular transducer, due to its synthetic simplicity, acceptable spectroscopic properties and the possibility of direct introductioninto solid phase peptide synthesis (SPPS). Since the parental peptide does not have a defined structure, we decided to introduce A MPB following an amino acid scan strat egy (Figure 3 ). The set of peptidomometics was prepared following the standard Fmoc-solid phase methodology and the synthesis of AMPB was carried out following literature procedures.[10] All the peptidomimetics showed fast and reversible photoisomerization and the thermal cis to trans relaxation was a rather slow process compatible with our biological experiments (data not shown).

To evaluate the binding affinities of the peptidomimetics to WDR5, a fluorescence polarization-based assay was used. The binding affinities are summarized in Figure 3, demonstrating that the trans isomer has always a higher affinity to WDR5 than its corresponding cis i somer. In addition, the influence of the introduced AMPB decreased when it is located far from the -ARA- motif. The peptidomimetic 5 shows the best binding affinity and one of the best differences between isomers. Gratifyingly, we observed that compound 5 had even one magnitude higher affinity than the parental peptide 1.[6]

\begin{tabular}{|c|c|c|c|}
\hline Peptides & $\begin{array}{c}\text { Non-irr. } \\
\text { (trans) } \\
\mathrm{K}_{\mathrm{i}}(\mathrm{nM})\end{array}$ & $\begin{array}{c}\text { Irr. at } \\
366 \mathrm{~nm} \\
\text { (cis) } \\
\mathrm{K}_{\mathrm{i}}(\mathrm{nM})\end{array}$ & $\begin{array}{l}\text { cis/ } \\
\text { trans }\end{array}$ \\
\hline $\begin{array}{c}\mathrm{H}_{2} \mathrm{~N} \text {-SARAEVHLRKS-CONH2 } \\
\mathbf{1}\end{array}$ & $\begin{array}{c}20.0 \pm \\
0.98\end{array}$ & $\begin{array}{c}24.5 \pm \\
0.49\end{array}$ & n.c. \\
\hline $\begin{array}{c}\mathrm{H}_{2} \mathrm{~N}-\mathrm{SXARAEVHLRKS}-\mathrm{CONH}_{2} \\
\mathbf{2}\end{array}$ & n.c & n.c & n.c. \\
\hline $\begin{array}{c}\mathrm{H}_{2} \mathrm{~N}-\mathrm{S} X \text { RAEVHLRKS-CONH} \\
\mathbf{3}\end{array}$ & $66.8 \pm 10$ & $432 \pm 73$ & 6.48 \\
\hline $\begin{array}{c}\mathrm{H}_{2} \mathrm{~N} \text {-SARXEVHLRKS-CONH} \\
\mathbf{4}\end{array}$ & n.c & n.c & n.c. \\
\hline $\begin{array}{c}\mathrm{H}_{2} \mathrm{~N} \text {-SARAXVHLRKS-CONH} \\
\mathbf{5}\end{array}$ & $\begin{array}{c}1.25 \pm \\
0.36\end{array}$ & $\begin{array}{c}6.50 \pm \\
1.4\end{array}$ & 5.00 \\
\hline $\begin{array}{c}\mathrm{H}_{2} \mathrm{~N} \text {-SARAEXHLRKS-CONH } \\
\mathbf{6} \\
\end{array}$ & $\begin{array}{c}2.40 \pm \\
0.60\end{array}$ & $\begin{array}{c}9.10 \pm \\
2.2\end{array}$ & 3.79 \\
\hline $\begin{array}{c}\mathrm{H}_{2} \mathrm{~N} \text {-SARAEVXLRKS-CONH } \\
\mathbf{7}\end{array}$ & $\begin{array}{c}40.4 \pm \\
3.9\end{array}$ & $\begin{array}{c}39.7 \pm \\
0.35\end{array}$ & 0.99 \\
\hline $\begin{array}{c}\mathrm{H}_{2} \mathrm{~N} \text {-SARAEVHXRKS-CONH } \\
\mathbf{8}\end{array}$ & $\begin{array}{c}17.0 \pm \\
1.9\end{array}$ & $\begin{array}{c}33.3 \pm \\
4.2\end{array}$ & 1.96 \\
\hline $\begin{array}{c}\mathrm{H}_{2} \mathrm{~N} \text {-SARAEVHLXKS-CONH } \\
9\end{array}$ & $\begin{array}{c}32.8 \pm \\
4.5\end{array}$ & $\begin{array}{c}70.4 \pm \\
6.6\end{array}$ & 2.15 \\
\hline $\begin{array}{c}\mathrm{H}_{2} \mathrm{~N} \text {-SARAEVHLRXS-CONH } \\
10 \\
10\end{array}$ & $\begin{array}{c}19.8 \pm \\
1.7\end{array}$ & $\begin{array}{c}40.6 \pm \\
2.5\end{array}$ & 2.05 \\
\hline
\end{tabular}
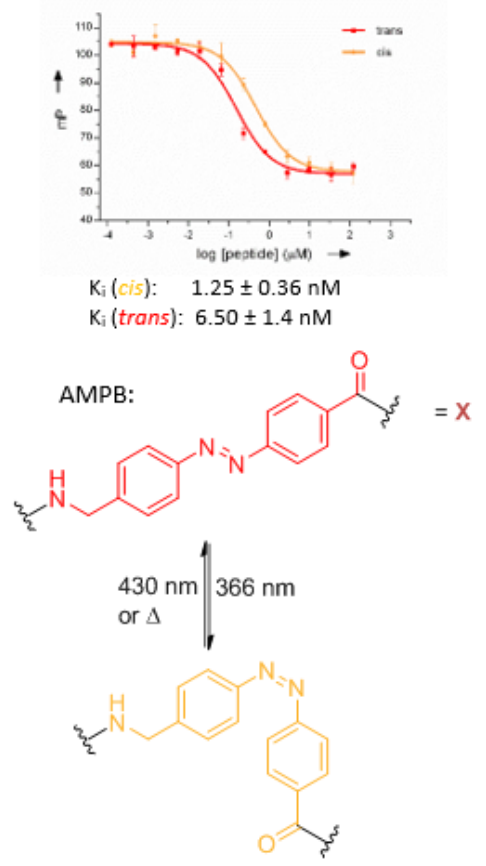

Figure 3: Left: Table with summarized Ki values for peptidomimetics 1-10. Mean values from three indepen-dent measurements. n.c. = not calculable (low binding affinity). Right, top: dose-dependent curve of best peptidomimetic 5. Bottom: photoswitching of AMPB molecule. 
To have a molecular interpretation of this increase in affinity, we determined the co-crystal structure of WDR5 in complex with trans peptidomimetic 5. In Figure 4 the interactions of the parent WIN peptide with the arginine side chain sandwiched between the two phenylalanines, are displayed. The overlay of the crystal structure of peptidomimetic 5 shows that the key interactions with the WDR5 protein agree well with the WIN peptide/WDR5 complex. However, from the glutamate onwards the orientation is different. The replacement of the solvent exposed glutamate residue by the AMPB provided additional stabilization through van der Waals interactions between the benzene ring of the AMPB with the aromatic side chain of Tyr260 and a hydrogen bond between the first nitrogen atom of AMPB and Lys259.
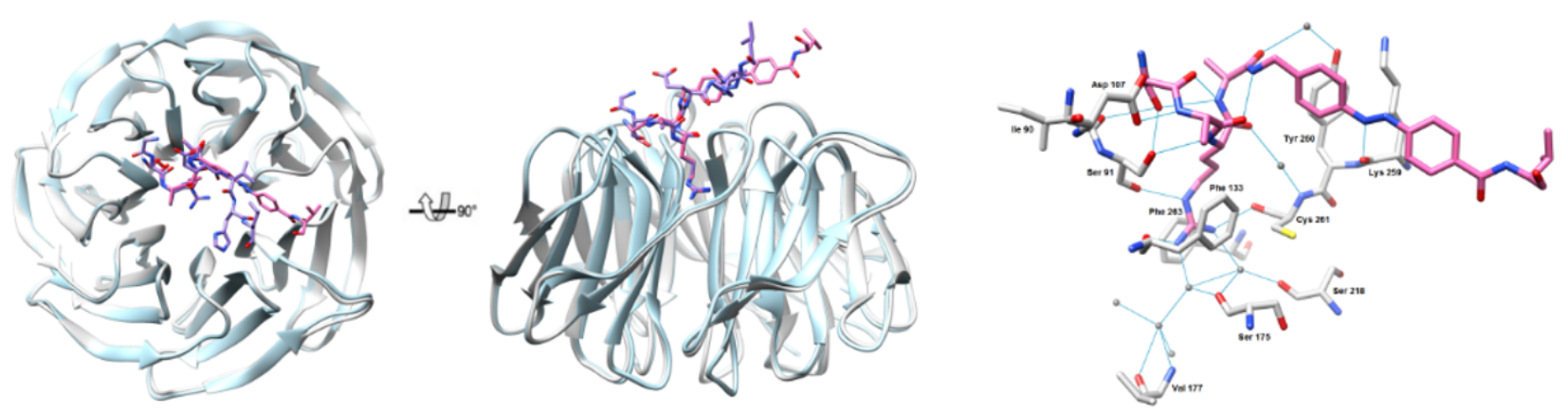

Figure 4: Co-crystal structure of WDR5 and peptidomimetic 5. Left: Overlay of WDR5/WIN peptide (purple) and WDR5/peptidomimetic 5 (pink). Right: Display of hydrogen bonds of peptidomimetic 5 to WDR5.

To determine whether our peptidomimetic 5 is not only binding to WDR5, but also able to inhibit the methylation activity of MLL1, we performed radioactive histone methyltransferase (HMT)-Assay. We could prove that the perturbation of the WDR5-MLL1 PPI by compound 5 was sufficient to inhibit the activity of MLL1 and, importantly, the difference in $\mathrm{IC}_{50}$ has turned up to higher than 15 fold.[6]

Next, we wanted to investigate if peptidomimetic 5 could inhibit leukemic cell proliferation, wherefore we prepared the photoswitchable peptidomimetic 5 connected to a cell penetrating peptide (CPP) to enable cell uptake. We showed, that the original WIN peptide, even connected to the same CPP, is not able to inhibit cell proliferation, whereas our probe is, indeed, able to downregulate leukemic cell proliferation significantly. Moreover, we observed a modest but clear difference between isomers, even with in situ cell irradiation (Figure 6).[6] 


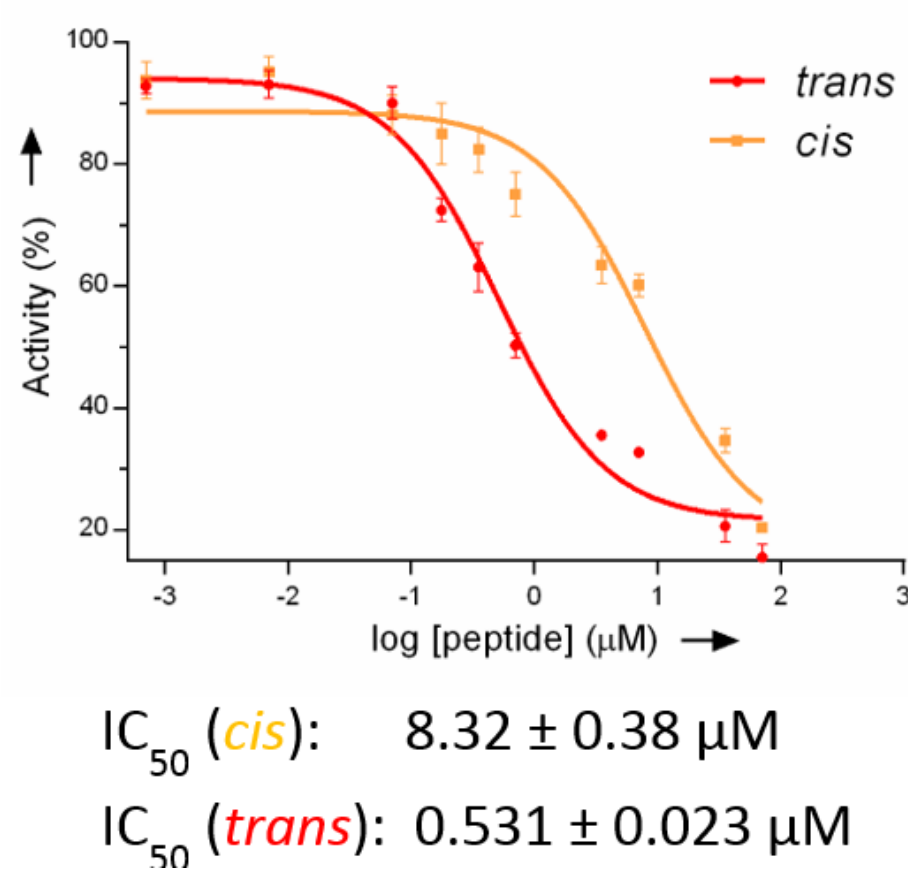

Figure 5: HMT-Assay of peptidomimetic 5 with MLL1 core complex.

Finally, we evaluated whether our probe can act as an optoepigenetic regulator and is able to control the expression of MLL1-target genes. Gratifyingly, we showed that the expression of deptor gene is significantly downregulated and observed a small but statistically significant $(p=0.008)$ difference between isomers. (Figure 6).[6]

In summary, our results are proof-of-concept of a new strategy for indirect external epigenetic control through targeting PPIs within a multi-protein complex. Our work highlights the importance of peptidomimetics as efficient alternatives to small molecule inhibitors and opens the door to PPIs as drugable targets.
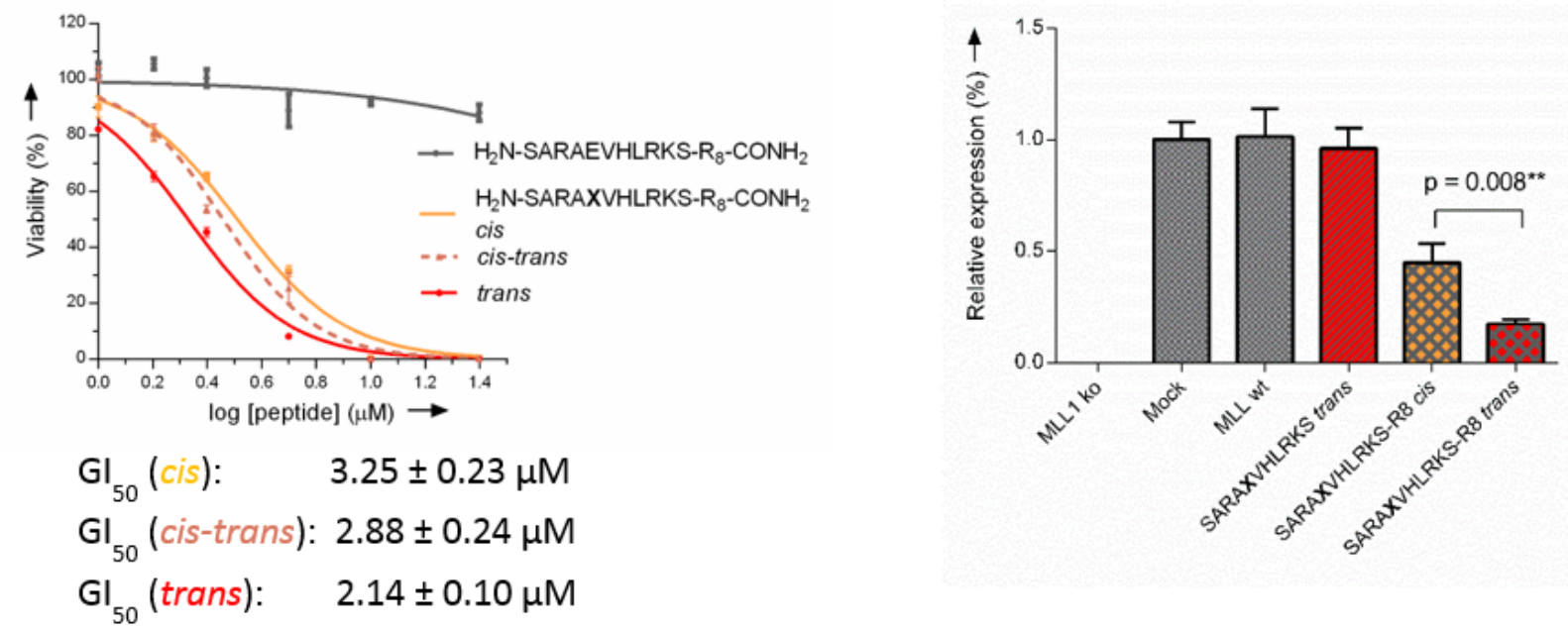

Figure 6: Left: Cell proliferation of MAF9 leukemia cells. Right: qPCR of MLL1 target gene deptor (GAPDH used as internal standard) 


\section{References}

[1] T. A. Milne, S. D. Briggs, H. W. Brock, M. E. Martin, D. Gibbs, C. D. Allis, J. L. Hess, Mol. Cell 2002, 10, $1107-1117$.

[2] Y. Dou, T. A. Milne, A. J. Ruthenburg, S. Lee, J. W. Lee, G. L. Verdine, C. D. Allis, R. G. Roeder, Nat. Struct. Mol. Biol. 2006, 13, 713-719.

[3] M. Vedadi, L. Blazer, M. S. Eram, D. Barsyte-Lovejoy, C. H. Arrowsmith, T. Hajian, Protein Sci. 2017, 26, 662-676.

[4] G. De Vita, P. Barba, N. Odartchenko, J. C. Givel, G. Freschi, G. Bucciarelli, M. C. Magli, E. Boncinelli, C. Cillo, Eur. J. Cancer 1993, 29, 887-893.

[5] D. Waltregny, Y. Alami, N. Clausse, J. De Leval, V. Castronovo, Prostate 2002, 50, 162-169.

[6] L. Albert, J. Xu, R. Wan, V. Srinivasan, Y. Dou, O. Vázquez, Chem. Sci. 2017, 8, 4612-4618.

[7] W. Szymanski, M. E. Ourailidou, W. a. Velema, F. J. Dekker, B. L. Feringa, Chem. - A Eur. J. 2015, 21, 16517-16524.

[8] S. a Reis, B. Ghosh, J. A. Hendricks, D. M. Szantai-Kis, L. Törk, K. N. Ross, J. Lamb, W. Read-Button, B. Zheng, H. Wang, et al., Nat. Chem. Biol. 2016, 12, 6-15.

[9] H. Karatas, E. C. Townsend, D. Bernard, Y. Dou, S. Wang, J. Med. Chem. 2010, 53, 5179-5185.

[10] B. Priewisch, K. Rück-Braun, J. Org. Chem. 2005, 70, 2350-2352. 